\title{
Variabile în acceptabilitatea variantelor tranzitive ale verbelor de schimbare de stare cu cauză internă în română ${ }^{\dagger}$
}

\author{
Maria Poponeț* \\ Facultatea de Litere, Universitatea „Babeș-Bolyai”, Str. Horea 31, 400202 Cluj-Napoca, România
}

\author{
Despre articol \\ Istoric: \\ Primit 4 iulie 2018 \\ Acceptat 11 august 2018 \\ Publicat 7 octombrie 2018 \\ Cuvinte-cheie: \\ verbe de schimbare de stare \\ cu cauză internă \\ acceptabilitatea tranzitivului \\ denotația subiectului \\ grup de vîrstă \\ valență
}

\begin{abstract}
Rezumat
Lucrarea studiază acceptabilitatea variantelor tranzitive pentru o serie de verbe de schimbare de stare, aparent cu cauză internă, în română: verbele exprimă evenimente de schimbare de stare și nu prezintă variante tranzitive. În acest scop, am creat un chestionar lingvistic ce testează acceptabilitatea corespondentelor tranzitive ale acestor verbe, în care am alternat denotația argumentului subiect: forță naturală vs. agent. Rezultatele obținute de la cei 33 de participanți la studiu arată influența factorilor semantici asupra acceptabilității tranzitivelor. Respondenții au considerat drept marginale tranzitivele cu subiecte forțe naturale, respingînd tranzitivele cu subiecte agent. Pe de altă parte, acceptabilitatea tranzitivelor variază in funcție de vîrsta participanților, valorile mici acordate tranzitivelor testate, indiferent de denotația argumentului subiect, de către cel mai tînăr grup de participanți indică menținerea valenței actuale a acestor verbe.
\end{abstract}

\section{Introducere}

În cadrul unei abordări lexicaliste a interfeței dintre sintaxă și semantică, Levin \& Rappaport Hovav (1995) sugerează clasificarea verbelor de schimbare de stare în verbe de schimbare de stare cu cauză externă și verbe de schimbare de stare cu cauză internă. În limbile naturale, cele două clase de verbe se definesc printr-o serie de trăsături semantice, sintactice și morfologice.

Astfel, verbele de schimbare de stare cu cauză externă „presupun existența unei «cauze externe»cu control direct asupra eventualității denotate de verb” (Levin \& Rappaport Hovav, 1995, p. 92), în timp ce verbele de schimbare de stare cu cauză internă denotă evenimente în care „o proprietate inerentă argumentului verbului este «responsabilă» pentru declanşarea eventualităţii” (Levin \& Rappaport Hovav, 1995, p. 91).

Levin \& Rappaport Hovav (1995, p. 94) propun următoarea reprezentare semantică lexicală pentru verbele de schimbare de stare cu cauză externă:

\section{(1) [[x FACE-CEVA] CAUZEAZĂ [y DEVINE STARE]]}

După cum reiese din (1), reprezentarea semantică lexicală a unui verb de schimbare de stare cu cauză externă este diadică, fiind alcătuită din două subevenimente: un subeveniment cauzator [x FACE-CEVA] și un subeveniment de schimbare de stare [y DEVINE STARE]. Fiecare subeveniment conține o variabilă argument, al cărei rol semantic este dictat de poziția ocupată în reprezentarea semantică lexicală: x aparține subevenimentului cauzator și are rolul semantic cauză, în timp ce y aparține subevenimentului de schimbare de stare și este pacient.

Un verb de schimbare de stare cu cauză externă se derivă din reprezentarea semantică lexicală diadică din (1) prin legarea lexicală ${ }^{1}$ a argumentului x în cartarea dintre reprezentarea semantică lexicală și structura argumentală. Legarea lexicală surprinde faptul că există o cauză externă în evenimentul exprimat

\footnotetext{
${ }^{\dagger}$ Mulțumesc revizorilor anonimi ai acestui articol pentru discuții și comentarii.

*Adresă de corespondență:maria_pop07@yahoo.com.

${ }^{1}$ Legarea lexicală este sinonimă cu cuantificarea existențială (Levin \& Rappaport Hovav, 1995, p. 108).
} 
de intranzitiv. De exemplu, în cazul unui verb de schimbare de stare cu cauză externă ca break „a se sparge” din engleză „,conform cunoștințelor noastre despre lume, eventualitatea nu putea să aibă loc fără o cauză externă” (Levin \& Rappaport Hovav, 1995, p. 93). Este important de reținut faptul că intranzitivul break ,a se sparge” are o reprezentare semantică lexicală diadică, în timp ce structura sa argumentală este monadică.

Ținînd cont de derivarea de la baze tranzitive ${ }^{2}$, verbele de schimbare de stare cu cauză externă prezintă variante tranzitive și intranzitive și iau parte la alternanța cauzativă [ilustrată în (2a,b)], fenomen manifestat de perechile de verbe înrudite semantic, cu variante tranzitive și intranzitive, în care tranzitivul precizează cauza evenimentului de schimbare de stare exprimat de intranzitiv ${ }^{3}$.

(2) a. John broke the window.

Ion a spart DET geam

„Ion a spart geamul.”

b. The window broke.

DET geam s-a spart

„Geamul s-a spart.”

În limbile cu morfologie anticauzativă (Haspelmath, 1993), verbele de schimbare de stare cu cauză externă tind să fie marcate morfologic.

Pe de altă parte, reprezentarea semantică lexicală a verbelor de schimbare de stare cu cauză internă este monadică, constînd într-un singur eveniment [y DEVINE STARE], cu argumentul pacient y, după cum este reprezentat în (3):

(3) [y DEVINE STARE]

Verbele de schimbare de stare cu cauză internă sînt la bază intranzitive care de obicei nu au corespondente tranzitive, indiferent de denotaţia argumentului subiect, agent [în (4b) și (5b)] sau forță naturală [în (4c) și $(5 c)$ ]. În consecință, aceste verbe nu iau parte la alternanța cauzativă.

(4) a. The cactus bloomed/blossomed/flowered early.

DET cactus a înflorit devreme

"Cactusul a înflorit devreme."

b. *The gardener bloomed/blossomed/flowered the cactus early.

DET grădinar a înflorit DET cactus devreme

"Grădinarul a înflorit cactusul devreme."

c. *The warm weather bloomed/blossomed/flowered the cactus early.

DET caldă vreme a înflorit DET cactus devreme

„Vremea caldă a înflorit cactusul devreme.”

(5) a. The logs decayed.

DET bușteni au putrezit

„Buștenii au putrezit.”

b. *The rangers decayed the logs.

DET pădurari au putrezit DET bușteni

„Pădurarii au putrezit buștenii.”

\footnotetext{
${ }^{2}$ În scopul detranzitivizării verbelor, tipul evenimentului cauzator trebuie să rămînă nespecificat (Levin \& Rappaport Hovav, 1995, p. 107).

${ }^{3}$ Participarea la alternanța cauzativă este considerată a fi un diagnostic al inacuzativității (Levin \& Rappaport Hovav, 1995), ipoteza care postulează verbe inacuzative: verbe intranzitive ale căror subiecte de suprafaţă sînt la bază obiecte (Perlmutter, 1978; Burzio, 1986).

${ }^{4}$ Limbile cu morfologie anticauzativă marchează membrii intranzitivi ai perechilor alternante.
} 


c. *The bad weather decayed the logs.
DET rea vreme a putrezit DET bușteni

„Vremea rea a putrezit buștenii.”

[Levin \& Rappaport Hovav, 1995, p. 97, (34a,b,c)]

Pe scurt, după cum au arătat datele de mai sus din engleză, verbele de schimbare de stare cu cauză externă exprimă evenimente cauzate din exterior și prezintă variante tranzitive, în timp ce verbele de schimbare de stare cu cauză internă exprimă evenimente cauzate din interior și nu prezintă variante tranzitive. Avînd în vedere că doar verbele de schimbare de stare cu cauză externă au variante tranzitive, participarea la alternanța cauzativă este rezervată acestei clase.

În secțiunea următoare vom analiza o serie de verbe de schimbare de stare din română care nu prezintă variante tranzitive și par să aparțină clasei de verbe de schimbare de stare cu cauză internă. Examinarea proprietăţilor acestor verbe, cu accent pe acceptabilitatea variantelor tranzitive, poate fi relevantă nu doar pentru stabilirea valenței verbelor investigate, dar și pentru adecvarea postulării verbelor de schimbare de stare cu cauză internă.

\section{Verbele de schimbare de stare cu cauză internă în română}

În limba română există verbe intranzitive de schimbare de stare care nu prezintă variante tranzitive (cu semnificația corespunzătoare) conform Dicționarului explicativ al limbii române (DEX) ${ }^{5}$, din care am selectat următoarele verbe: a se cloci, a se prinde (laptele), a înflori, a germina, a năpîrli, a înmuguri, a (se) putrezi, a (se) mucegăi, a (se) rugini.

Pentru început, verbele par să respecte criteriul semantic asociat verbelor de schimbare de stare cu cauză internă, dat fiind faptul că verbele descriu procese chimice și biologice naturale, cauzate de proprietăți ale entității subiect.

Pe de altă parte, unele verbe, a se cloci și a se prinde (laptele), sînt marcate în mod obligatoriu cu morfologie reflexivă, fapt ce indică derivarea de la o variantă tranzitivă (Haspelmath, 1993; Levin \& Rappaport Hovav, 1995; Chierchia, 2004).

Avînd în vedere că aceste argumente morfologice pun sub semnul întrebării intranzitivitatea de bază a verbelor a se cloci și a se prinde (laptele), în cele ce urmează, vom examina adecvarea valenței fixe (unicitatea intranzitivității) verbelor din română enumerate mai sus.

\subsection{Variabile semantice in acceptabilitatea variantelor tranzitive pentru verbele de schimbare de stare cu cauză internă}

Metodologia utilizată a constat în colectarea de judecăți de acceptabilitate (anterior numite judecăți de gramaticalitate, v. Schütze \& Sprouse, 2013) pentru versiunile tranzitive ale verbelor enumerate mai sus, în care am alternat denotaţia entității aflate în poziția de subiect: forță naturală vs. agent. Așadar, am urmărit corectitudinea gramaticală a propozițiilor dependentă de factori semantici ce țin de denotația entităţilor din poziția de subiect.

33 de vorbitori de limbă română, cu vîrste cuprinse între 20 și 50 de ani, au participat la studiu. Aceștia au completat un chestionar lingvistic în care au acordat unui număr de 18 propoziții o valoare pe o scală de la 1 la 5 (o scală Likert cu cinci trepte), unde 1 simbolizează „Complet inacceptabilă”, 2 simbolizează „Aproape inutilizabilă”, 3 înseamnă „Discutabilă”, 4 înseamnă „Aproape perfectă”, 5 semnifică „Perfectă” 6 . Aceste judecăți de acceptabilitate graduale sînt compatibile cu un model de gramatică în trepte (Schütze \& Sprouse, 2013), ce presupune mai multe niveluri de acceptabilitate gramaticală, spre deosebire de modelul tradițional cu granulație mare care avea doar două opțiuni: „negramatical' și „gramatical”. Astfel,

\footnotetext{
${ }^{5}$ Vezi și Dragomirescu (2010) pentru clasificarea verbelor inacuzative din română.

${ }^{6}$ Opțiunile din scala Likert cu cinci trepte sînt inspirate din Geber (2011), dar am inversat numerotarea autoarei: opțiunea terminală „Complet inacceptabilă” primește cea mai mică valoare 1, în timp ce opțiunea terminală „Perfectă” primește cea mai mare valoare 5, și am înlocuit opțiunea „3. Nici bună, nici rea” cu „3. Discutabilă”.
} 
participanților li s-a cerut să acorde o valoare propozițiilor, conform gramaticii proprii, pe o scală ce se desfășoară între opțiunea terminală „Complet inacceptabilă” și opțiunea terminală „Perfectă”.

Am calculat media de acceptabilitate a fiecărei propoziții, constînd în media ponderată, și am inclus valoarea minimă și valoarea maximă obținută de fiecare propoziție. Dat fiind faptul că este posibil ca propozițiile să primească o gamă variată de valori, am considerat că este util să includem modul, adică valoarea acordată cel mai frecvent fiecărei propoziții.

Tabela 1 cuprinde rezultatele obținute de la cei 33 de vorbitori chestionați.

\begin{tabular}{lllll} 
Propoziție & Medie & Min. & Max. & Mod \\
\hline 1. Căldura a clocit apa. & 2,87 & 1 & 5 & 3 \\
2. Ion a clocit apa. & 1,39 & 1 & 4 & 1 \\
3. Căldura a prins (coagulat) laptele. & 3,06 & 1 & 5 & $2 ; 4$ \\
4. Gospodina a prins (coagulat) laptele. & 2,21 & 1 & 4 & 1 \\
5. Căldura a înflorit pomii. & 2,81 & 1 & 5 & 1 \\
6. Grădinarul a înflorit pomii. & 1,33 & 1 & 3 & 1 \\
7. Căldura a germinat grîul. & 2,78 & 1 & 5 & 3 \\
8. Ion a germinat grîul. & 1,45 & 1 & 3 & 1 \\
9. Căldura a năpîrlit păsările. & 2,12 & 1 & 5 & 1 \\
10. Îngrijitorul a năpîrlit păsările. & 1,66 & 1 & 5 & 1 \\
11. Căldura a înmugurit pomii. & 3,06 & 1 & 5 & 3 \\
12. Grădinarul a înmugurit pomii. & 1,30 & 1 & 3 & 1 \\
13. Ploaia a putrezit lemnele. & 2,75 & 1 & 5 & 3 \\
14. Ion a putrezit lemnele. & 1,03 & 1 & 2 & 1 \\
15. Umezeala a mucegăit pîinea. & 3,33 & 1 & 5 & 5 \\
16. Ion a mucegăit pîinea. & 1,42 & 1 & 5 & 1 \\
17. Umezeala a ruginit tabla. & 3,48 & 1 & 5 & $4 ; 5$ \\
18. Ion a ruginit tabla. & 1,54 & 1 & 5 & 1
\end{tabular}

Tabela 1: Statistică descriptivă a rezultatelor testului de acceptabilitate a variantelor tranzitive pentru verbele de schimbare de stare cu cauză internă

Deși aceste verbe sînt considerate a fi exclusiv intranzitive conform DEX, unii respondenți tind să accepte variantele tranzitive cu subiecte forțe naturale precum căldura, ploaia sau umezeala. Astfel, cînd subiectele sînt forțe naturale, tranzitivele a cloci (propoziția [1]), a prinde (propoziția [3]), a înflori (propoziția [5]), a germina (propoziția [7]), a înmuguri (propoziția [11]), a putrezi (propoziția [13]), a mucegăi (propoziția [15]), a rugini (propoziția [17]) au fost considerate discutabile, rotunjind valoarea medie obținută de fiecare propoziție la cel mai apropiat număr întreg ${ }^{7}$, în aceste situații, numărul 3. Cu subiect non-agent, tranzitivul a năpîrli (propoziția [9]) a fost socotit aproape inutilizabil (media 2). A mucegăi înregistrează modul 5; a rugini înregistrează modurile 4 și 5; a cloci, a germina, a inmuguri, a putrezi au modul 3; a prinde are modurile 2 și 4; a inflori și a năpîrli au modul 1.

$\mathrm{Cu}$ subiecte agent, tranzitivele a cloci (propoziția [2]), a inflori (propoziția [6]), a germina (propoziția [8]), a înmuguri (propoziția [12]), a putrezi (propoziția [14]), a mucegăi (propoziția [16]) au fost evaluate drept complet inacceptabile (media 1), în timp ce a prinde (propoziția [4]), a năpîrli (propoziția [10]), a rugini (propoziția [18]) au fost considerate aproape inutilizabile (media 2). Modul acestor verbe tranzitive cu subiecte agent este 1 , ceea ce înseamnă că cei mai mulți vorbitori au considerat aceste propoziții complet inacceptabile.

Tranzitivele cu subiecte forțe naturale au obținut întreaga serie de valori (propozițiile [1], [3], [5], [7], [9], [11], [13], [15], [17] au primit valori de la 1 la 5). Doar unele tranzitive cu subiecte agent au înregistrat întreaga serie de valori (propozițiile [10], [16], [18] au obținut valori de la 1 la 5), în timp ce

\footnotetext{
${ }^{7}$ În continuare, vom utiliza mediile obținute de propoziții rotunjite la cel mai apropiat număr întreg.
} 
valoarea maximă înregistrată de majoritatea celorlalte a fost mai mică decît 5 (propozițiile [2] și [4] au obținut valoarea maximă 4; propozițiile [6], [8], [12] au înregistrat valoarea maximă 3; propoziția [14] a obținut valoarea maximă 2 ).

După cum arată aceste date, tranzitivele cu subiecte forțe naturale se află pe o poziție mai înaltă pe scala acceptabilității decît tranzitivele cu subiecte agent. Rezultatele noastre sînt în conformitate cu ideile avansate de Levin (2009), care susţine că verbele de schimbare de stare cu cauză internă în engleză uneori prezintă variante tranzitive cu subiecte forțe naturale, dar nu cu subiecte agent ${ }^{8}$. De obicei, agenții nu pot manipula forțe naturale cum sînt căldura, ploaia sau umezeala, fapt pentru care agenții nu pot constitui cauze directe ale evenimentelor aparent cu cauză internă și nu pot fi subiecte ale acestor tranzitive. Pe de altă parte, căldura, ploaia sau umezeala pot fi interpretate drept cauze directe ale acestor evenimente, după cum arată judecățile vorbitorilor chestionați care au considerat drept marginale tranzitivele cu subiecte forțe naturale.

Argumentaţia din Levin (2009) este în concordanță cu viziunea general acceptată în literatura de specialitate conform căreia cauzativele lexicale ${ }^{9}$ exprimă cauzare directă (dar vezi Neeleman \& van de Koot, 2012, pentru o opinie diferită $)^{10}$. Astfel, subiectele cauzativelor lexicale sînt considerate a fi cauze directe ale evenimentului de schimbare exprimat de verb.

Chestionarul lingvistic utilizat a oferit respondenților posibilitatea de a corecta propozițiile considerate mai puțin acceptabile și de a sugera alternative. Rectificările includ utilizarea versiunilor intranzitive ale acestor verbe, cauzele fiind introduse în grupuri adjunct cu centrul din cauza, din pricina, datorită, de la, de sau la. Unii participanți au evitat utilizarea agenților în cadrul grupurilor adjunct cu centrul din cauza sau datorită, probabil pentru că nu consideră că agenții reprezintă cauze ale acestor evenimente. Alți participanți au recurs la cauzative analitice/perifrastice cu centrul a face ca alternative la cauzativele lexicale testate.

\subsection{Variabile in funcție de vîrsta participanților in acceptabilitatea variantelor tranzitive pentru verbele de schimbare de stare cu cauză internă}

O variabilă de care trebuie să se țină cont în discuția valenței verbelor este vîrsta vorbitorilor chestionați. Astfel, credem că valorile mari acordate variantelor tranzitive de către vorbitorii mai tineri indică o schimbare a valenței acestor verbe.

Cei 33 de participanți la studiu formează trei grupuri, în funcție de vîrstă: grupul de vîrstă între 20-25 de ani, grupul de vîrstă între 26-35 de ani și grupul de vîrstă între 36-50 de ani. Fiecare grup de vîrstă este alcătuit din 11 membri.

Participanții din grupurile de vîrstă între 26-35 de ani și 36-50 de ani au studii universitare, iar cei din grupul de vîrstă între 20-25 de ani fie au finalizat studiile universitare, fie sînt studenți. Dat fiind faptul că din punctul de vedere al educației grupul este omogen, nivelul de educație nu a reprezentat o variabilă în analiza judecăților de acceptabilitate. În plus, participanții nu au studii aprofundate de lingvistică, astfel încît judecăţile lor nu au fost influențate de considerații teoretice familiare lingviștilor.

În cele ce urmează, vom analiza comparativ mediile obținute de cele 18 propoziții discutate mai sus, în funcție de grupul de vîrstă al participanților, ilustrate în Tabela 2.

După cum arată datele, diferența dintre mediile tranzitivelor cu subiecte forțe naturale și mediile tranzitivelor cu subiecte agent este mai mare în cadrul grupului de vîrstă între 36-50 de ani. Acest grup consideră că majoritatea tranzitivelor cu subiecte forțe naturale sînt discutabile: propozițiile [1], [3], [5],

\footnotetext{
${ }^{8}$ McKoon \& Macfarland (2000, 2002) au identificat exemple atestate de variante tranzitive pentru verbele de schimbare de stare cu cauză internă din engleză. Am întîlnit exemple atestate în care tranzitivul a putrezi apare cu subiecte forțe naturale ca apa în (i). Un studiu amplu al corpusului este necesar în viitor.
}

(i) Apa corodează oțelul, putrezește lemnul. (casasidesign.ro)

\footnotetext{
${ }^{9}$ Din punct de vedere sintactic, cauzativele lexicale sînt verbe tranzitive.

${ }^{10}$ Vezi și Wolff (2003) referitor la codarea lingvistică a evenimentelor cauzate direct.
} 


\begin{tabular}{lllll} 
Propoziție & $\begin{array}{l}\text { Medie } \\
(20-25 \text { ani })\end{array}$ & $\begin{array}{l}\text { Medie } \\
(26-35\end{array}$ & $\begin{array}{l}\text { Medie } \\
(36-50 \text { ani) }\end{array}$ & Medie \\
\hline 1. Căldura a clocit apa. & 2,18 & 3,09 & 3,36 & 2,87 \\
2. Ion a clocit apa. & 1,54 & 1,63 & 1,00 & 1,39 \\
3. Căldura a prins (coagulat) laptele. & 2,45 & 3,27 & 3,45 & 3,06 \\
4. Gospodina a prins (coagulat) laptele. & 2,09 & 2,18 & 2,36 & 2,21 \\
5. Căldura a înflorit pomii. & 2,27 & 3,09 & 3,09 & 2,81 \\
6. Grădinarul a înflorit pomii. & 1,54 & 1,45 & 1,00 & 1,33 \\
7. Căldura a germinat grîul. & 2,27 & 3,27 & 2,81 & 2,78 \\
8. Ion a germinat grîul. & 1,72 & 1,54 & 1,09 & 1,45 \\
9. Căldura a năpîrlit păsările. & 2,27 & 2,45 & 1,63 & 2,12 \\
10. Îngrijitorul a năpîrlit păsările. & 2,45 & 1,63 & 1,00 & 1,66 \\
11. Căldura a înmugurit pomii. & 2,72 & 3,27 & 3,18 & 3,06 \\
12. Grădinarul a înmugurit pomii. & 1,63 & 1,27 & 1,00 & 1,30 \\
13. Ploaia a putrezit lemnele. & 2,36 & 3,00 & 2,90 & 2,75 \\
14. Ion a putrezit lemnele. & 1,09 & 1,00 & 1,00 & 1,03 \\
15. Umezeala a mucegăit pîinea. & 3,18 & 3,63 & 3,18 & 3,33 \\
16. Ion a mucegăit pîinea. & 1,63 & 1,54 & 1,09 & 1,42 \\
17. Umezeala a ruginit tabla. & 3,18 & 3,54 & 3,72 & 3,48 \\
18. Ion a ruginit tabla. & 1,81 & 1,72 & 1,09 & 1,54
\end{tabular}

Tabela 2: Statistică descriptivă a rezultatelor testului de acceptabilitate a variantelor tranzitive pentru verbele de schimbare de stare cu cauză internă distribuite pe grupuri de vîrstă

[7], [11], [13], [15] au obținut media 3; propoziția [17] a înregistrat media 4 (aproape perfectă); propoziția [9] a înregistrat media 2 (aproape inutilizabilă). Tranzitivele cu subiecte agent au fost respinse într-o manieră mai categorică de către acest grup, comparativ cu celelalte două grupuri: media propozițiilor [2], [6], [8], [10], [12], [14], [16], [18] este 1 (complet inacceptabile), iar media propoziției [4] este 2 (aproape inutilizabilă).

Prin comparație, diferența dintre mediile tranzitivelor cu subiecte forțe naturale și mediile tranzitivelor cu subiecte agent este mai mică în cadrul grupului de vîrstă între 26-35 de ani. Tranzitivele cu subiecte forțe naturale din propozițiile [1], [3], [5], [7], [11], [13] au media 3 (discutabile), cele din propozițiile [15] și [17] au media 4 (aproape perfecte), iar tranzitivul din propoziția [9] a înregistrat media 2 (aproape inutilizabil). Tranzitivele cu subiecte agent din propozițiile [2], [4], [8], [10], [16], [18] au obținut media 2 (aproape inutilizabile), iar cele din [6], [12], [14] au obținut media 1 (complet inacceptabile).

Diferența dintre mediile tranzitivelor cu subiecte forțe naturale și mediile tranzitivelor cu subiecte agent este cea mai mică în cadrul grupului de vîrstă între 20-25 de ani. Tranzitivele cu subiecte forțe naturale din propozițiile [1], [3], [5], [7], [9], [13] au înregistrat media 2 (aproape inutilizabile), iar cele din [11], [15], [17] au înregistrat media 3 (discutabile). Tranzitivele cu subiecte agent din propozițiile [2], [4], [6], [8], [10], [12], [16], [18] au obținut media 2 (aproape inutilizabile), in timp ce tranzitivul din propoziția [14] a obținut media 1 (complet inacceptabil).

Acceptabilitatea tranzitivelor cu subiecte forțe naturale înregistrează valori ridicate în cadrul grupului de vîrstă între 36-50 de ani (7 propoziții au fost considerate discutabile (3), 1 a fost evaluată aproape perfectă (4)), are cele mai mari valori în cadrul grupului de vîrstă între $26-35$ de ani ( 6 propoziții au fost considerate discutabile (3), 2 au fost evaluate aproape perfecte (4)), înregistrînd cele mai scăzute valori în cadrul grupului de vîrstă între $20-25$ de ani (6 propoziții au fost considerate aproape inutilizabile (2), 3 au fost evaluate discutabile (3)).

Pe de altă parte, tranzitivele cu subiecte agent au înregistrat cele mai mici medii în cadrul grupului de vîrstă între 36-50 de ani (8 propoziții au fost considerate complet inacceptabile (1), 1 a fost evaluată 
aproape inutilizabilă (2)), urmat de grupul de vîrstă între 26-35 de ani (3 propoziții au fost considerate complet inacceptabile (1), 6 au fost evaluate aproape inutilizabile (2)) și de grupul de vîrstă între 20-25 de ani ( 1 propoziție a fost considerată complet inacceptabilă (1), 8 au fost evaluate aproape inutilizabile (2)).

Deși este necesară chestionarea unui număr mai mare de vorbitori înainte de a face generalizări, respingerea variantelor tranzitive ale verbelor de schimbare de stare cu cauză internă, indiferent de denotația argumentului subiect (forță naturală sau agent), de către grupul cel mai tînăr de participanți pare să indice tendința de a menține valența verbelor testate.

\section{Concluzii}

Studiul nostru relevă faptul că acceptabilitatea variantelor tranzitive ale verbelor de schimbare de stare cu cauză internă în română depinde de denotația argumentului subiect. Astfel, tranzitivele cu subiecte forțe naturale se află la mijloc pe scala de acceptabilitate (o scală Likert cu cinci trepte), în timp ce tranzitivele cu subiecte agent se apropie de opțiunea terminală de inacceptabilitate.

Totuşi, respingerea într-o manieră mai categorică a variantelor tranzitive ale acestor verbe de către grupul cel mai tînăr de participanți pare să indice menținerea valenței actuale a verbelor.

Deși intranzitivitatea de bază a verbelor care nu sînt marcate cu morfologie reflexivă poate avea o motivație semantică, dat fiind faptul că verbele exprimă evenimente cu cauză internă în lume, marcarea morfologică a verbelor a se cloci și a se prinde (laptele) rămîne fără explicație în contextul în care aceste verbe nu au tranzitive complet acceptabile. Totuși, verbele prezintă variante tranzitive cu semnificații diferite (vezi DEX), de la care probabil că derivă aceste semnificații specializate. Cu toate că este posibil ca intranzitivele a se cloci și a se prinde (laptele), marcate în mod obligatoriu cu morfologie reflexivă, să fie derivate de la tranzitivele a cloci și a prinde, cele dintîi au dezvoltat semnificații specializate ale căror tranzitive nu sînt complet acceptabile. Verbele care sînt în mod obligatoriu marcate cu morfologie reflexivă și, posibil, verbele cu marcare morfologică opțională (a (se) putrezi, a (se) mucegăi, a (se) rugini) arată că există doar o corelație parțială între verbele de schimbare de stare cu cauză internă și marcarea morfologică.

\section{Bibliografie}

Burzio, L. (1986). Italian Syntax: A Government and Binding Approach, Reidel, Dordrecht.

Chierchia, G. (2004). A Semantics for Unaccusatives and its Syntactic Consequences, în A. Alexiadou, E. Anagnostopoulou \& M. Everaert (eds), The Unaccusativity Puzzle: Explorations of the Syntax-Lexicon Interface, Oxford University Press, Oxford, p. 22-59, Crossref.

DEX = Dicționarul explicativ al limbii române, [online].

Dragomirescu, A. (2010). Ergativitatea: Tipologie, sintaxă, semantică, Editura Universității din Bucureşti, Bucureşti.

Geber, D. (2011). Romanian Dative Clitic Dependencies in Raising Constructions, Teză de doctorat, Universitatea din Ottawa.

Haspelmath, M. (1993). More on the Typology of Inchoative/Causative Verb Alternations, în B. Comrie \& M. Polinsky (eds), Causatives and Transitivity, John Benjamins, Amsterdam, p. 87-120, Crossref.

Levin, B. (2009). Further Explorations of the Landscape of Causation: Comments on the Paper by Alexiadou and Anagnostopoulou, în Proceedings of the Workshop on Greek Syntax and Semantics, MIT Working Papers in Linguistics, Cambridge, p. $239-266$.

Levin, B. \& Rappaport Hovav, M. (1995). Unaccusativity: At the Syntax-Lexical Semantics Interface, MIT Press, Cambridge.

McKoon, G. \& Macfarland, T. (2000). Externally and Internally Caused Change of State Verbs, în „Language”, vol. 76, nr. 4, p. 833-858, Crossref.

McKoon, G. \& Macfarland, T. (2002). Event Templates in the Lexical Representation of Verbs, în „Cognitive Psychology”, vol. 45, p. 1-44, Crossref.

Neeleman, D. \& van de Koot, H. (2012). The Linguistic Expression of Causation, în M. Everaert, M. Marelj \& T. Siloni (eds), The Theta System: Argument Structure at the Interface, Oxford University Press, Oxford, p. 20-51, Crossref.

Perlmutter, D. (1978). Impersonal Passives and the Unaccusative Hypothesis, în J.J. Jaeger et al. (eds), Proceedings of the Fourth Annual Meeting of the Berkeley Linguistics Society, Berkeley Linguistics Society, Berkeley, p. 157-189.

Schütze, C.T. \& Sprouse, J. (2013). Judgment Data, în R.J. Podesva \& D. Sharma (eds), Research Methods in Linguistics, Cambridge University Press, Cambridge, p. 27-50, Crossref.

Wolff, P. (2003). Direct Causation in the Linguistic Coding and Individuation of Causal Events, în „Cognition”, vol. 88, p. 1-48, Crossref. 